\title{
A DESIGUALDADE EM PERSPECTIVA SOCIOESPACIAL: NOTAS E REFLEXÕES EM TORNO DE UMA REALIDADE COMPRESSIVA E CONFLITUAL
}

BAGGIO, Ulysses da Cunha ${ }^{1}$

BAGGIO, Ulysses da Cunha. A Desigualdade em Perspectiva Socioespacial: Notas e Reflexões em Torno de uma Realidade Compressiva e Conflitual. Revista Científica Multidisciplinar Núcleo do Conhecimento. Ano 1. Vol. 9. Pp. 564-603. Outubro / Novembro de 2016. ISSN. 2448-0959

\section{RESUMO}

O artigo se devota a uma análise da desigualdade em suas implicações socioespaciais, procurando mostrar a recorrência desse tema na história, procurando apontar as distinções entre diferenciação e desigualdade, não raro tomadas como expressões sinônimas pelo senso comum. A análise enfatiza o avanço e o próprio redimensionamento da desigualdade na esteira do capitalismo e de formação do mundo-moderno, pondo em relevo o sentido correlato adquirido pela desigualdade, que se consubstancia em sua inter-relação com o espaço, metabolizando-se, assim, como desigualdade socioespacial, estreitamente associada ao movimento contraditório e desigual do capitalismo, que alcança maturidade com a consolidação da urbanização da sociedade. Tal urbanização, tornada extensiva e geograficamente dispersa e difusa sob os influxos do capitalismo monopolista, passa a representar a própria espacialização societária contemporânea. Vale ressaltar que essa urbanização extensiva, consolidada pela industrialização fordista até fins dos anos 1960 e início dos 70, se atualiza, ao mesmo tempo em que se complexifica no contexto de crise/esgotamento do padrão de acumulação fordista e do desenvolvimento de um novo padrão de acumulação, de traço flexível-espoliativo, desempenhando um papel central a profusão de novas tecnologias de informação e comunicação, bem como

${ }^{1}$ Professor doutor do Departamento de Geografia da UFV. 
uma espetacular financeirização da economia, num quadro de profusa expansão territorial da terceirização, que matizam o estágio atual da globalização capitalista, conducente a uma urbanização mais espraiada, com a multiplicação e expansão de cidades médias, entabulando uma nova urbanização de feição metropolitana, que aproxima geograficamente as desigualdades, a pobreza e a riqueza, sob o sentido de uma oposição conflituosa e degradante. A análise destaca a inserção e o papel da periferia no processo de formação do sistema-mundo, revelando-se não como um estágio, momento ou circunstância do desenvolvimento histórico do capitalismo, mas fundamentalmente como um espaço integrado a ele, ou ainda como uma função ou condição imprescindível à estrutura de seu próprio funcionamento e sustentação. Tal abordagem nos leva a situar o sistema-mundo capitalista como uma totalidade socioespacial intrinsecamente contraditória e desigual, no qual a reprodução e expansividade da periferia, ou talvez, de periferias, assinalam uma característica estrutural da espacialidade capitalista. Na periferia, sob o movimento de contradições mais recrudescidas, em que pesem os influxos de mudanças estruturais nas formas de organização do trabalho, ao lado de reestruturações vultosas no espaço, principalmente em grandes espaços urbanos, embasadas na associação entre o capital financeiro e o imobiliário, que contam com a coordenação do Estado, ao que se soma a proeminência da lógica rodoviarista e seus impactos no território, temos, assim, o avanço, a passos rápidos, de um conjunto de situações urbanístico-sociais problemáticas em nossas cidades, em aspectos diversos, que apontam, sob um sentido social, para o agravamento de uma urbanização crítica, que acirra desigualdades, privações e expropriações. Do ponto de vista do capital, premido por condições de desvalorização do ciclo depressivo atual do capitalismo, estas operações se mostram como novas frentes de valorização do capital, impondo um descompasso entre a escala do valor econômico (valor de troca) e a do valor de uso (relacionado a aspectos qualitativos) no/do espaço. Sob esta condição, temos emergências de novas formas de resistência, lutas e organização social, influindo modalidades político-espaciais que encetam, ao plano da vida cotidiana, uma diversidade de ações de caráter propositivo nos interstícios da urbe, tanto em espaços centrais como periféricos, tratam-se de práticas que se mostram dotadas, em boa 
parte, de certo traço auto-organizacional ou mesmo autogestionário. Considerandose que não necessariamente negam o Estado, estas práticas são compreendidas como vetores capazes de potencializar a democracia e transformações socioespaciais mais desejadas pela sociedade, sinalizando um contraponto auspicioso ao problema da desigualdade na contemporaneidade, se não delineando uma via alternativa num contexto marcadamente estatista e privado-corporativo.

\section{INTRODUÇÃO}

Historicamente, ao plano da organização das sociedades humanas, a desigualdade (aqui compreendida como uma realidade compressivo-conflitual diretamente relacionada às relações de poder) se apresenta como preocupação desde a Antiguidade, causando inquietações a importantes pensadores gregos, tais como Platão e Aristóteles, passando por filósofos-teólogos da Idade Média, a exemplo de Santo Agostinho e São Thomas de Aquino, percorrendo o período de transição do feudalismo para o capitalismo, com Thomas Hobbes, estendendo-se pelo lluminismo, com destaque às reflexões de Rousseau, em seu "Discurso sobre a origem e os fundamentos da desigualdade entre os homens", avançando pelo século XVIII, com o pensamento idealista de Hegel, notadamente em sua perspectiva política e dialética do movimento da história, mas também pela sólida análise de Karl Marx, o qual se debruçou sobre a organização social, política e econômica de seu tempo, elaborando uma análise crítica teoricamente rigorosa da sociedade capitalista, sob um profundo sentido de indignação em torno das condições de desigualdade baseadas na divisão de classes, propugnando a sua transformação através da luta social revolucionária, desigualdade que também foi analisada nos estudos do sociólogo e economista alemão Max Weber, sob uma perspectiva mais complexa da estratificação social, pela qual identificava os componentes basilares da formação da desigualdade social. No campo da Geografia, área de nossa atuação, o tema da desigualdade social apresenta-se como um problema antigo, podendo-se destacar as contribuições dos geógrafos anarquistas Élisée Reclus e Piotr Kropotkin, os quais se defrontaram com as causas e os problemas da desigualdade social de seu tempo (século XIX), preconizando outra forma de sociedade, alternativa e mais igualitária. Nos tempos

Disponível em: https://www.nucleodoconhecimento.com.br/ciencias-sociais/realidade-compressiva$\underline{\text { e-conflitual }}$ 
hodiernos, não poderíamos deixar de destacar aqui na América Latina e, mais especificamente, no Brasil, o geógrafo Milton Santos, através de amplos estudos sobre o território desigual, a globalização corporativa e os direitos do cidadão. Em outras áreas encontramos ainda estudiosos e pensadores que, em muito, se nutriram do legado de Hegel e, sobretudo, de Marx, tais como Lênin, Gramsci, Luckács. Diversos outros estudiosos, em campos variados do conhecimento, se ocuparam também do assunto ao longo do século XX e início do XXI, não sendo, no entanto, nosso propósito nesse trabalho fazer uma espécie de inventário circunstanciado e exaustivo sobre aqueles que, de forma destacada, trataram do tema da desigualdade social em suas expressões e implicações na sociedade e no espaço, mas tão somente chamar a atenção para o fato de que tal tema se apresenta como uma preocupação recorrente na história, evidenciando, de forma inequívoca, a sua relevância na análise da sociedade e dos processos sociais, envolvendo uma variedade de enfoques e perspectivas teórico-metodológicas.

\section{DIFERENCIAÇÃO E DESIGUALDADES SOCIOESPACIAIS}

Partindo-se do pressuposto de que a sociedade em seu movimento encerre histórica e ontologicamente uma correspondente espacialidade, dada pela criação de um espaço ou âmbito espacial por formas de organização e produção sociais, pode-se asseverar que as diferenciações sociais se projetam no espaço como um traço marcante de sua realização histórica, que avança pelos lugares (lugar aqui compreendido como instância imediata do drama social) sob a forma de um processo essencialmente desigual e contraditório, ou ainda como um desenvolvimento espacial e geograficamente desigual. Sua realização se dá pela ação simultânea de vetores de homogeneização, fragmentação e hierarquização, em cujo movimento formas espaciais e processos sociais estão indissociável e dialeticamente articulados, compondo, assim, uma interação estrutural do espaço organizado. Por conseguinte, a constituição desta estrutura reflete tanto uma homologia espacial, uma vez que ambas as variáveis desta relação decorrem das mesmas origens no modo de produção capitalista, como a conformação de uma unidade marcadamente dialética entre elas, dada pela inseparabilidade entre o espacial e o social, sugerindo-nos, 
portanto, uma dupla dimensionalidade nesta associação, respectivamente horizontal e vertical (SOJA, 1993, p.99-100).

Depreende-se, assim, que a organização espacial é a própria objetivação das relações sociais em sua interface metabólica com a natureza, representando uma dimensão da totalidade social historicamente produzida, na qual a natureza é transformada pelo trabalho social; o que vale dizer que a organização espacial resulta de uma dialética sociedade/espaço. E, embora o espaço possa mostrar-se como algo "primordialmente dado", sua organização e seu sentido inscrevem-se como um "produto da translação, da transformação e da experiência sociais" (SOJA, 1993, p.101). Isso revoga compreensões que fetichizam o espaço, afastando-se da idéia de que ele possa operar quaisquer determinismos no processo social. Ademais, à medida que a organização espacial está submetida a uma sociedade de classes ela, efetivamente, reflete "tanto a natureza classista da produção e do consumo de bens materiais, como o controle exercido sobre as relações de classes sociais que emergiram das relações sociais ligadas à produção" (CORREA, 1986, p.55-56). Daí ela expressar uma diversidade de conformações espaciais criadas pelo trabalho social, que, no entanto, acrescentaríamos, sofrem interferências dos contextos político-institucionais em que são constituídas, conferindo-lhes especificidades e traços de diferenciação.

Historicamente, as diferenciações sociais existentes, precipuamente as produzidas no meio urbano, cristalizam-se de forma processual no espaço-tempo, ou ainda, no mundo prático-sensível como disparidades socioespaciais, que não se confundem, bem entendido, como uma mera "diferenciação de áreas". Tais disparidades se assentam e decorrem, em larga medida, da divisão social do trabalho, comparecendo, historicamente, como espacializações diferenciais produzidas pela variabilidade dos influxos das interações sociedade-natureza. Isso não quer dizer, ressalte-se, que suas expressões na realidade se circunscrevam tão somente aos seus componentes empíricos, ou seja, como manifestações auto-evidentes na paisagem, haja vista também serem constituídas por elementos abstratos, como, por exemplo, fluxos de dinheiro virtual, de informações, ideologias, etc. Tais conformações sugerem-nos a 
idéia de uma totalidade intrinsecamente variável, inerente ao processo de produção capitalista do espaço, com maior destaque no processo de urbanização de países periféricos ou de capitalismo tardio.

Depreende-se, pois, que a diferenciação social e, de forma mais específica, a desigualdade socioespacial que ela recobre (categorias cujos significados são diferentes, mas que, ao plano do senso comum, são tomadas como expressões sinônimas, o que é uma distorção), integra a história dos povos, não se tratando de uma característica exclusiva de uma dada sociedade ou de determinado sistema sócio-econômico. De modo constante e variável, sob as especificidades dos contextos socioespaciais, elas acompanham a dinâmica evolutiva das sociedades, grafando-as em seus respectivos espaços de existência.

Sob o desenvolvimento do capitalismo, no entanto, as diferenciações e, especialmente, as desigualdades adquirem um novo sentido e novas expressões, alcançando maiores complexidade, contrastes e visibilidade. Tamanha variabilidade ocorre, sobretudo, na esteira da consolidação do processo de urbanização, principalmente no período após Segunda Guerra, com um desenvolvimento mais robusto do capitalismo monopolista e suas vertentes de modernização coordenadas pelo Estado. A partir daí esta urbanização se torna extensiva. Ela representa uma transformação socioespacial de amplas proporções, que implica, entre outros aspectos, na subordinação do campo pela cidade (LEFEBVRE, 1999), amplificandose, assim, o fenômeno urbano. Com ele, nos diz Henri Lefebvre, o "tecido urbano" prolifera e se difunde, corroendo "os resíduos da vida agrária", não se restringindo, com efeito, "ao domínio edificado nas cidades", mas recobrindo "o conjunto das manifestações do predomínio da cidade sobre o campo" (1999, p.17), configurando limites cada vez mais imprecisos e intrincados entre o urbano e o rural. Correlacionadamente, a urbanização extensiva também expressa a generalização do mundo da mercadoria, sob um espetacular desenvolvimento das forças produtivas e das redes, potencializando tanto vetores de horizontalização como de verticalização do capital e do processo social no espaço. Tais transformações redimensionam e fortalecem as contradições fundamentais do capitalismo, tais como entre capital e 
trabalho, estendendo-se aos campos do consumo coletivo e da reprodução social. Nesse contexto, tanto as diferenciações territoriais como as desigualdades socioespaciais redimensionam-se e adquirem maior complexidade. Na América Latina e, mais especificamente no Brasil, verifica-se que com o avanço do neoliberalismo, sobretudo a partir dos anos 1990, recrudesce-se a desigualdade e, de forma associada, a segregação socioespacial, o que está diretamente relacionado ao redirecionamento, pelo Estado, das políticas públicas ao suporte praticamente exclusivo aos segmentos mais competitivos, numa economia já bastante desigual, recobrindo grande transferência de recursos públicos à iniciativa privada, impondo às populações mais empobrecidas maiores restrições de acesso a serviços básicos.

Impõe-se esclarecer, então, que nem toda diferença é desigualdade e vice-versa, estando o sentido de diferença estreitamente associado à identificação da essência do que se coloca em comparação, em sua totalidade ou sob certos aspectos parciais, podendo ser tanto de ordem nata e natural como cultural. A desigualdade, por sua vez, pressupõe em sua definição a variável da circunstância, âmbito no qual se estabelecem social e politicamente as distinções essenciais do que se compara, conotando, de modo geral, o sentido de injustiça social, portanto também de conflito. Nessa perspectiva, a desigualdade implica em situações de diferenciação entre pessoas e entre segmentos da sociedade, tanto em uma mesma sociedade como entre sociedades outras, de países ou mesmo regiões diferentes. Desse modo, ela revela que parcelas de uma dada sociedade se coloquem hierárquica e estruturalmente em melhores condições do que outras. Considerando que as desigualdades sociais se mostrem em esferas diversas da sociedade, tais como da cultura, vida política, cotidiano, economia, etc., não se pode perder de vista, no entanto, que o espaço, à medida que compreende todas as demais instâncias da sociedade, projetando-se no real como uma totalidade integrada e dialética, faz com que tais manifestações se transmutem em expressões espacializadas, percebidas e compreendidas também como desigualdades socioespaciais.

De forma mais específica, temos que a desigualdade que se produz na esteira do desenvolvimento do capitalismo e de formação do mundo-moderno é aquela que: 
[...] "se assenta na posse centralizada da riqueza social gerada por toda a sociedade nas mãos de uma classe social, que é também detentora do poder, o que permite estabelecer as condições de sua reprodução numa aliança entre os planos político e econômico contra o social" (CARLOS, 2015, p.43).

Por conseguinte, sob uma perspectiva moderna a desigualdade socioespacial apresenta-se, então, estreitamente associada ao movimento contraditório e desigual que marca a lógica de desenvolvimento e realização socioespacial do capitalismo, refletindo-a na esteira de sua dinâmica evolutiva, alcançando maturidade com a consolidação da urbanização da sociedade. Generalizando-se desigualmente pelo mundo, esta urbanização representa a própria espacialização societária da modernidade, marcadamente complexa e prenhe de contradições e vicissitudes. Não sem razão a periferia estar inserida na formação do sistema-mundo não como um estágio, momento ou circunstância no processo de desenvolvimento do capitalismo, mas integrada a ele como uma função ou condição à estrutura de seu próprio funcionamento e sustentação, o que nos leva a compreender o sistema-mundo capitalista como uma totalidade socioespacial intrinsecamente contraditória e desigual, no qual a reprodução e expansividade da periferia, ou talvez, de periferias, assinalam uma característica estrutural da espacialidade capitalista, que se inscreve na lógica da própria sobrevivência do capitalismo.

A propósito, Ernest Mandel, ao se debruçar sobre as desigualdades regionais do capitalismo, assevera que "o sistema mundial capitalista é, em grau considerável, precisamente uma função da validade universal da lei de desenvolvimento desigual e combinado" (1985, p.14 grifo do autor), apresentando-a como a própria essência do capitalismo e colocando-a no mesmo grau de importância que a exploração da mãode-obra pelo capital. Constituindo uma das leis da dialética, entendida como interpenetração dos contrários, as contradições resultantes do desenvolvimento desigual e combinado operam no processo histórico como forças motores à sua própria transformação. 
No que concerne ao espaço, tal desenvolvimento se projeta como processos de diferenciação socioterritorial, engendrando condições à realização de regionalizações. Vale dizer que estes processos, indubitavelmente, alcançam maior contundência e complexidade sob o modo de produção capitalista, sobretudo em sua fase atual, marcado pela globalização, que assim se redimensionam pela simultaneidade de vetores de coesão e fragmentação, integração e diferenciação. Com efeito, tal movimento de diversificação socioterritorial, dado por conformações espaço-regionais desigualmente articuladas, reafirma e atualiza o próprio princípio da unidade e diversidade na História.

A lógica contraditória intrínseca à lei do desenvolvimento desigual e combinado estabelece uma dinâmica socioespacial irrequietamente contraditória, marcada pela sucessão de processos de construção, destruição e recomposição de estruturas espaciais em diferentes partes do mundo, do mesmo modo que em porções de uma mesma formação territorial, daí podendo resultar a constituição de regiões ou de expressões regionais, a exemplo do que se verifica mais contemporaneamente na formação de complexos urbano-metropolitanos, que se conformam sob certa feição regional. Estamos, assim, diante de uma dinâmica socioespacial que avança e se reestrutura sob o sentido de uma produção/reprodução contínua e diferencial de uma "segunda natureza", intensamente submetida às dinâmicas de valorização do capital (sobretudo do capital financeiro em associação com outras frações do capital), refletindo-as flagrantemente ao plano da reprodução do espaço, processo que engendra conflitos e contradições que, sob essa lógica, se tornam mais recrudescidos, assinalando, assim, particularidades à socialização capitalista na periferia.

No que importa às contradições engendradas na esteira do desenvolvimento desigual e combinado, Mandel identifica potenciais revolucionários ou de transformação, quando reitera que "a contradição entre o crescimento das forças produtivas e a sobrevivência das relações de produção capitalistas assume uma forma explosiva", conduzindo o capitalismo "a uma crise cada vez mais acentuada dessas relações de produção" (1985, p.393). Compreendendo-a como uma "crise social global", com o sentido de uma "decadência histórica de todo um sistema social e de modo de 
produção", conducente ao recrudescimento das desigualdades espaciais (que ele compreendia como necessárias à acumulação capitalista), Mandel aponta para a emergência de "uma nova tendência de lutas de classe cotidianas, capaz de transformar os conflitos enfrentados em ponto de partida de movimentos anticapitalistas de massa" (p.407), contestando "cada vez mais os valores fundamentais e as prioridades do modo de produção capitalista também em nível social" (p.409).

A análise empreendida por Mandel proporciona subsídios importantes, entre outros aspectos, quanto à formação, em curso, de uma espacialidade efetivamente diferencial e desigual no capitalismo, que não apenas remete ao recrudescimento das contradições socioespaciais nos países de capitalismo tardio, como é o caso do Brasil, como, de forma diretamente relacionada, contribui substancialmente à própria requalificação e atualização dos estudos regionais, permitindo-nos, nessa perspectiva, contradizer e indagar idéias apressadas quanto a uma suposta homogeneização dos lugares e dos espaços; idéias com as quais não compactuamos, é forçoso assinalar, posto que a realização têmporo-espacial do capitalismo comporta, simultaneamente, tanto vetores tendentes a certa homogeneização, recobrindo componentes de repetição e de relativa regularidade de fenômenos do processo econômico e social, como vetores de diferenciação subjacentes ao mesmo, vetores que integram, dialeticamente, um duplo movimento de desintegração/preservação de estruturas socioespaciais historicamente constituídas, mantendo-se intacta a lógica de produção e reprodução do desenvolvimento espacialmente desigual.

Isso significa, então, que a realização socioespacial do capitalismo, de orientação intensivo-expansiva sob a globalização de égide financeira, tanto implica como se vale da diferenciação e da própria desigualdade à sua reprodução e manutenção, para o que a "condição periférica", a que uma grande parcela de países do mundo está submetida, desempenha um papel fundamental. Tal condição define uma "posição subordinada na hierarquia dos lugares na economia-mundo capitalista", de modo a que os espaços sujeitados a relações de poder, sejam por forças externas ou por 
causas internas, se não ambas, possam proporcionar a obtenção de super-lucros a diferentes formas de exploração e acumulação do capital (MORAES, 2005, p.83).

Vale lembrar que a reprodução ampliada do lucro do capital é o motor da dinâmica econômica do capitalismo, cujos atores contemporâneos são proeminentemente corporações, pessoas jurídicas que, de modo geral, são de propriedade coletiva, tais como as "sociedades anônimas", cujas atividades são marcadas pela alta competição, coerção e exploração, movidas pelo desejo obsessivo de expansão ilimitada e crescimento contínuo (CAPRA, 1995). Crescimento que "mesmo quando se faz presente e poderia, a priori, parecer uma boa notícia", pode ser tudo, "exceto um longo rio tranquilo", haja vista que as inovações técnicas em que ele se apoia "não apenas perturbam de alto a baixo nossos costumes e nossos modos de viver", como também "criam inevitavelmente o desemprego, as desigualdades, e até mesmo, paradoxo supremo, o decrescimento! " (FERRY, 2015, p.22). Acerca disso, a ocorrência de crises de desvalorização, com o decréscimo da taxa de lucro, advinda de situações de superprodução, com a saturação do mercado em termos de oferta, bem o demonstra, expondo-nos, assim, que o processo de produção encerra contradições que the são inerentes. Contradições estas que reverberam sensivelmente no espaço, advindas essencialmente "do conteúdo prático e social e, especificamente, do conteúdo capitalista", prenhe de conflitos, entre um espaço que se pretende racional e o espaço mais imediato em que se desenrola o drama social, pelo qual ele é percebido, vivido, mas também fragmentado e comercializado sob as interferências do capital e do Estado (LEFEBVRE, 2008, p.57).

\section{DESIGUALDADE SOCIOESPACIAL E PERIFERIA}

As consequências socioespaciais do poder adquirido pelas corporações ou grandes conglomerados econômicos dão evidências de se mostrarem ainda mais nocivas em países periféricos (vide, por exemplo, o episódio recente do rompimento da barragem da mineradora Samarco em Mariana, Minas Gerais), contando com a tutela explícita ou tácita do Estado, que atua muito mais como uma espécie de sócio maior ou preferencial dessas empresas do que como agente fiscalizador e regulador. Sendo 
emblemático o caso brasileiro, essa situação desnuda no país um explícito debilitamento da capacidade de governar do Estado, expondo a exaustão dos arranjos político-institucionais vigentes e o esgotamento da economia, sinalizando para um efetivo descontrole regulatório do Estado em relação às empresas e seus empreendimentos no território. Acerca disso, temos que no Brasil de hoje, diferentemente das décadas desenvolvimentistas do período subseqüente à Segunda Guerra, especialmente entre os anos 1950-70, a maior parcela das empresas e seus empreendimentos no território perderam muito de seu controle pelo Estado. E é justamente na atuação associada das grandes empresas com atores políticos e elites locais e regionais, que operam sob a perspectiva do ganho econômico, que encontramos a chave ao controle corporativo do território, condição pela qual se multiplicam estratégias de apropriação da riqueza social, envolvendo o recrudescimento de práticas ilícitas e a preocupante escalada da cleptocracia no país, isto é, de um Estado no qual a nação deixa de ser governada por um Estado de Direito imparcial e se torna governada pelo poder discricionário de pessoas que passaram a controlar o poder político, transformando-o em valor econômico ou instrumentalizando-o para este fim. Em outras palavras, um Estado governado por ladrões, por gatunos que se valem de poderes e possibilidades conferidos por sua posição funcional na hierarquia do poder político e administrativo do Estado para operar práticas ilícitas, em conluio com o poder econômico e financeiro, devotadas à apropriação/acumulação de riqueza socialmente produzida, tratando-se de um sistema complexo de alta corrupção, sob o sentido de uma criminalidade organizada de alto nível instalada no aparelho de Estado. Sob esta condição as práticas de corrupção tornam-se sistêmica, operando como uma espécie de retrovírus da política, sinalizando, assim, à necessidade de reformas urgentes e inadiáveis, como a própria reforma política, dentre outras.

Considerando-se que a lógica de formação dessa espacialidade desigual também recubra e se reproduza em escalas sub-nacionais, como é o caso dos espaços urbanos, pode-se compreender do por que a periferia, com suas espacialidades, se apresentar no tempo e no espaço como uma espécie de obra inacabada, como um 
processo socioespacial que não cessa ou retrocede, antes, ao contrário, que se espraia e adquire grande complexidade e diversidade, com maior magnitude e clarividência em cidades médias e metrópoles. Transcendendo os limites da mera localização e da condição de comportar massivamente grafias da pobreza, a periferia vem se transformando rapidamente sob os influxos territoriais da valorização, incorporando, de modo ascensional, novas formas urbanas e funções, conformandose como um mosaico socioespacial bastante irrequieto. Esse aspecto, não raro, vem sendo considerado como algo que favoreceria ou induziria, sob os reclamos imperiosos da necessidade (muitas vezes negadas pelo Estado), efervescências político-culturais e práticas experimentais territorializadas, não raro de caráter propositivo, que buscam alcançar, ao seu modo e nos limites de suas possibilidades, visibilidade social e respostas, tanto quanto possível, a problemas e demandas cotidianamente vividos.

Todavia, vale lembrar que, historicamente, as periferias regionais e urbanas, do ponto de vista do capital e do Estado, desempenharam, e ainda desempenham a função de ofertar grandes contingentes de força de trabalho barata; força de trabalho essa, é importante salientar, que está na base da formação mais ampla da cidade e do território, em que vivem e se reproduzem todos os segmentos sociais, incluindo-se aí a produção das próprias periferias, quer seja como trabalho assalariado, quer como ajuda - mútua ou autoconstrução, e até mesmo como modalidades de trabalho análogas à escravidão, sobretudo na construção civil, com obras aí incluídas com financiamento público. A urbanização e a produção do território têm sido assim apoiadas em larga medida pela exploração massiva de grandes parcelas de força de trabalho barata e pobre, presentes massivamente nesses espaços periféricos, mas também, embora em menor grau, em espaços centrais de grandes centros urbanos, como populações que moram em cortiços. Desse modo, persistem ainda polaridades regionais entre riqueza e pobreza, do mesmo modo que a reprodução de disparidades a nível intra-regional e intra-urbano, com a novidade, nos tempos atuais, de que estas assimetrias estejam, sobretudo no âmbito intra-urbano, evoluindo espacialmente em sentido convergente, configurando uma aproximação tendencial entre as 
desigualdades socioespaciais, notadamente em países de industrialização/modernização tardias, podendo-se conferir destaque a cidades brasileiras, tais como São Paulo, Rio de Janeiro, Belo Horizonte, Salvador, Recife, etc., reveladoras de grandes contrastes socioespaciais.

Daí poder-se dizer que a estrutura mais geral do espaço urbano, em específico, se assenta efetivamente nas desigualdades sociais, revelando-as em sua diversidade, para o que a centralização e a concentração tendenciais do capital no espaço, que também se exercitam sobre os meios de produção e a riqueza, evidenciam o traço incisivamente contraditório e desigual que marca a urbanização e as cidades capitalistas. No meio urbano de sociedades periféricas essa totalidade desigual lhe é intrínseca, com a modernidade fundindo-se com a pobreza em um espaço bastante complexo e diversificado, expondo uma estrutura marcadamente híbrida, ambivalente e instável, mas, no entanto, muito dinâmica (BECKER; EGLER, 1994, p.170).

É bastante esclarecedor, nesse sentido, acompanharmos o processo de formação do território brasileiro e, mais especificamente, os termos como se deu o processo de modernização do Brasil, principalmente a partir dos anos 1930. Em linhas gerais, ela se traduziu numa modernização marcadamente centralizada, realizada de cima para baixo, embasada no pacto do Estado com elites econômicas, aspectos pelos quais ela se configurou como uma modernização conservadora, constituindo-se no eixo central de formação do Brasil moderno. Influindo mudanças estruturais a partir da esfera política, essa "modernização pelo alto" marcou a fundo a dinâmica evolutiva da formação do território brasileiro, recaindo-Ihe, assim, ações bastante seletivas do planejamento econômico estatal. Dentre outros aspectos, ela impulsionou uma rápida oligopolização da economia brasileira e grandes contrastes espaço-regionais, que se redefinem e se atualizam no presente sob a globalização neoliberal, expondo grandes oportunidades de investimento ao capital privado no território e uma busca quase que obsessiva pela inserção do Brasil nos mercados internacionais globalizados. Nesse sentido, se põe em curso o desenvolvimento de um novo padrão de acumulação no território nacional de caráter eminentemente econômico-empresarial, que instrumentaliza o território como rede e reafirma a sua condição como base de 
geração de valor, como mercadoria, subordinando, assim, sua dimensão enquanto valor de uso. A acumulação em curso no período atual representa, pois, uma forma de socialização capitalista da economia e do território que se objetiva por uma expressiva ampliação da base da propriedade privada, potencializando processos concentracionistas sob o comando dos grandes empreendimentos das corporações ou conglomerados econômicos.

Nesse contexto, e sob essa condição, avança uma forma de gestão do território e das cidades, mais especificamente, sob o sentido de negócio e como coisa para empreendedores, insuflando uma ampla privatização do espaço em moldes corporativos, movimento concentracionista pelo qual o espaço se consubstancia em espaço corporativo, podendo-se falar, do mesmo modo, em cidades corporativas. Tal lógica, pela nossa compreensão, agrega e potencializa impactos substanciais ao meio ambiente e a sócio-diversidade dos lugares, incitando degradações, conflitos e estranhamentos, ao mesmo passo que barreiras e fronteiras sociais, segregações e espoliações, aspectos marcantes da desigualdade socioespacial contemporânea, que se colocam no fulcro dos conflitos políticos de nossos tempos, precipuamente no que afeta à necessidade premente quanto à melhoria das condições de vida das populações mais empobrecidas, com a seguridade de direitos tangíveis a todos, e não a "princípios abstratos de justiça social" (PIKETTY, 2015, p.10).

Portanto, ao plano de sua realização o capitalismo não apenas opera de forma desigual e contraditória, como se vale e instrumentaliza as desigualdades, necessitando, assim, da própria pobreza, o que pode parecer paradoxal. Não sem razão temos que em pleno século XXI, sob um grande desenvolvimento das forças produtivas do capital, com notáveis avanços na ciência e na tecnologia, formas compulsórias de exploração do trabalho, análogas ao trabalho escravo, não apenas se mantêm como são reproduzidas, sobretudo em ciclos de crise, como o atual. Os exemplos se multiplicam no mundo, com milhões de pessoas submetidas a formas coercitivas de trabalho, tanto em ambientes urbanos como rurais, em confecções, construção civil, locais de prostituição, restaurantes, ambientes domésticos, olarias, pedreiras, carvoarias, áreas agrícolas, campos de exploração madeireira, etc., 
podendo-se oferecer como exemplos destacados os casos do Brasil, Haiti, América Central, México, China, Índia, Mianmar, Sudão, mas também Suécia, Reino Unido (Inglaterra, Escócia, País de Gales, Irlanda do Norte), Estados Unidos, entre outros. Isso significa que o processo de valorização do capital, sobretudo em espaços periféricos, implica na "produção capitalista de relações não-capitalistas de produção" (MARTINS, 1990), trazendo à tona implicações socioespaciais que thes são correspondentes, entabulando expressões localizadas mais específicas de valorização capitalista do espaço, escrevendo-Ihes certas particularidades.

\section{CAPITALISMO GLOBALIZADO DE ÉGIDE FINANCEIRA E EXPRESSÕES SOCIOESPACIAIS DA URBANIZAÇÃO EXTENSIVA}

Com o desenvolvimento do capitalismo globalizado e do intenso desenvolvimento das forças produtivas, amparados em redes de variados tipos, a urbanização da sociedade se consolidou e se potencializou, afirmando-se como uma urbanização extensiva ou expandida, transcendendo os limites das cidades, atingindo e submetendo o campo, tornando-se a cidade os lócus de praticamente tudo o que acontece no meio rural. Sob a urbanização capitalista as desigualdades socioespaciais comparecem como uma de suas principais expressões, engendrando historicamente a formação de segmentos sociais variados e modos igualmente distintos de apropriação da riqueza socialmente produzida, revelando, nesse sentido, a impossibilidade de apropriação de condições básicas de sobrevivência a parcelas expressivas da sociedade, objetivando-se, assim, na própria impossibilidade do urbano para todos, com parcelas cada vez maiores de pessoas submetidas a um conjunto de restrições e privações, estabelecendo modalidades de inserção perversa ou precária e exclusão. Tal situação, bem entendido, não se confunde com a idéia de uma crise de adequação ao urbano, aqui compreendido como "uma parte integrante e uma particularização da generalização contextual mais fundamental sobre a espacialidade da vida social" (SOJA, 1993, p.186). Portanto, não se pode perder de vista que as desigualdades socioespaciais estão fundamentadas na propriedade da terra e na apropriação privada, que se produzem na esteira da reprodução ampliada do capital e na 
transformação generalizada do espaço em mercadoria, e, não por acaso, ela encerrar não apenas um sentido de injustiça social como também de conflito social.

Daí poder-se asseverar que o próprio urbanismo tenha se convertido numa força da produção, que interfere e modifica as relações sociais, aí incluídas as de produção, porém não se mostrando suficiente, por si só, para transformá-las. Isso não significa, entretanto, tomar o urbano e, mais especificamente, o urbanismo sob o sentido da reificação do espaço. Não é demais dizer que o espaço é aqui compreendido no sentido de espaço socialmente organizado e construído, no qual "as relações sociais e espaciais são dialeticamente inter-reativas; interdependentes", ao mesmo tempo em que "as relações sociais de produção são formadoras do espaço e contingentes ao espaço" (SOJA, 1993, p.102-103).

O dinamismo alcançado pelo modo de produção capitalista consolida uma efetiva assincronia entre a esfera econômica e a política, na qual ganha preeminência a primeira, alçando a base econômica do processo social a um papel de comando, envolvendo um descompasso entre os processos econômicos e sociais que se dão no âmbito do nacional e do internacional e, de outro, as instituições que deveriam efetuar a sua regulação, acarretando, com efeito, perturbações entre estas instâncias. $\mathrm{O}$ que não autoriza afirmações quanto à existência de uma dualidade entre o econômico e o político, que, em realidade, não existe, haja vista o econômico pressupor relações sociais, sob uma relação dialética de dupla determinação. Tratase, mais propriamente, da imposição da racionalidade do mercado mundializado no processo político, instaurando progressivamente certa feição mercantil ao existencial e à vida cotidiana, por conseguinte recobrindo o espaço em escalas territoriais variadas. Tal imposição socioespacial representa a consolidação do mundo da mercadoria, entabulando condições à realização generalizada do processo de valorização.

Essa imposição do econômico em relação ao social implica na submissão do uso e do valor de uso ao valor de troca, o que responde pelo desenvolvimento processual de um conflito entre estas dimensões, com o uso e o valor de uso tornando-se 
subjugados pelo valor de troca. Com o espaço tornado mercadoria, afirma-se uma oposição antitética perturbadora entre elas, que não se revela tão somente no plano teórico, como bem o identificou Marx em alguns de seus textos, embora, cumpre esclarecer, ele não tenha chegado a estudar o capital de forma empírica; projetandose também, e cada vez mais, no mundo prático-sensível, objetivando-se desigualmente no tempo e no espaço.

Isso significa que existem diferentes possibilidades de apropriação do espaço e da cidade pelos atores sociais, refletindo suas posições na hierarquia social. Tais diferenciações se materializam na estrutura espacial e urbana, não raro suscitando tensões e conflitos ao plano do acesso a recursos importantes à vida e à reprodução social, a exemplo da moradia, transporte público, emprego, educação, saúde, lazer, etc., alimentando, assim, a segregação socioespacial e o conflito em torno de representações e percepções pelos diferentes agentes, que adquirem projeção na vida social.

Tornando-se, portanto, um dado da realidade objetiva, tal conflito marca a fundo a urbanização contemporânea, que avança com a multiplicação de modalidades de apropriação privada do espaço, podendo-se destacar as apropriações corporativas, ampliado substancialmente a base privada de sua realização. Dentre as implicações desse processo, essencialmente concentracionista, pode-se destacar o aumento de forças de compressão na vida cotidiana, reprodução social, meio ambiente e no espaço público, recrudescendo desigualdades e segregações socioespaciais. São componentes que operam na base da escalada da violência urbana e na formação de níveis elevados de mal-estar e estresse na cidade, ponto crítico que leva a marca do desemprego e do subemprego, da precarização das condições de trabalho, dos baixos salários e de condições deletérias do sistema educacional e de saúde público.

A formação ascensional de territórios e cidades corporativos guarda, pois, estreitas relações com a globalização atual de égide financeira, que impõe uma avassaladora financeirização da economia, com grande capilaridade no espaço, mais especificamente nos negócios em torno dele. Com efeito, o capital financeiro encontra 
na apropriação do espaço um suporte robusto ao seu resguardo e valorização, o que se define como uma estratégia reprodutiva, num ambiente marcadamente competitivo e com o capital submetido a processos de desvalorização, dando-nos, assim, o tom da crise capitalista contemporânea.

A título de exemplificação, veja-se o que acontece no segmento habitacional, com a difusão, mundo afora, de um mesmo paradigma, tornado dominante, que é o modelo de financeirização da moradia. Esse modelo tem levado, sob os influxos do neoliberalismo, ao desmonte dos sistemas públicos de habitação amparados pelo Estado, objetivando-se na implementação da casa própria individual com financiamento por créditos bancários, com bancos públicos ampliando formas de captação de investimentos para esse fim. A condição fundamental a essa situação reside na propriedade privada individual, possibilitando que a terra e a moradia consubstanciem-se num ativo financeiro, comercializável a escala planetária.

Os agentes financeiros protagonizam, portanto, um papel bastante importante no mercado habitacional, disponibilizando créditos à construção e à compra de imóveis, no qual os custos envolvidos são sensivelmente elevados. Daí o capital financeiro comparecer como um agente preeminente na formação do espaço construído, realizando-se por meio de sua reprodução. Esse processo se dá através de uma ampla articulação do capital financeiro com outras frações do capital (fundiário, industrial e comercial), que conta com a coordenação do Estado (CARLOS, 2015, p.57). Dessas operações é que provêm lucros e dinheiro acumulado que se redirecionam ao mercado financeiro, alimentando robustos investimentos na produção de novas formas urbanas e de novos espaços, tais como edifícios corporativos, requalificação de áreas centrais, de antigos espaços industriais, de áreas portuárias etc., operações que tanto potencializam a valorização da propriedade fundiária como favorecem condições mais gerais de circulação do valor, respondendo, portanto, pela reestruturação de parcelas expressivas da cidade, o que, não raro, tem implicado em expulsões e expropriações, subvertendo-se, assim, direitos sociais básicos, sob a chancela do Estado. Quase que invariavelmente as intervenções urbanísticas 
conduzidas pelo Estado têm contribuído substancialmente à ampliação da desigualdade socioespacial e das tensões na vida cotidiana urbana.

Vale lembrar que no conjunto das formas que compõem a estrutura urbana total o "fixo" habitacional é a principal e a mais extensiva das formas de uso do solo urbano, significando muito mais que simplesmente um abrigo, sendo também uma forma de inserção na cidade, não se resumindo a habitação tão somente à unidade habitacional, mas incluindo todas as demais formas construídas que compõem o espaço urbano (BAGGIO, 1995, p.5). O que nos sugere a idéia de pensar o universo habitacional como um sistema espaço-relacional, estruturalmente diverso e desigual, que reflete a própria estrutura de classes que marca a sociedade capitalista, fazendo com que o acesso aos bens e serviços socialmente produzidos se realize sob a marca da seletividade, ainda maior em sociedades da periferia do sistema-mundo, como a brasileira. E a habitação é um dos bens (mercadoria) a que expressivas parcelas da sociedade não têm acesso minimamente satisfatório, haja vista os baixos salários auferidos, numa economia que em essência é marcadamente de exploração e que, assim, não absorve a todos, fazendo multiplicar formas de inserção precária na sociedade e no espaço. No limite essa realidade assim se constitui dada a existência, de um lado, da super-exploração da força de trabalho, impondo grande restrição de renda a uma grande parcela da classe trabalhadora, e, de outro, a instituição da propriedade privada da terra e a organização do espaço pelo capital. As contradições e incompatibilidades daí resultantes empiricizam territorialmente a pobreza, engendrando a produção de um espaço urbano técnica, econômica e socialmente segregado. Nos países de industrialização tardia, especialmente, temos que essa contradição fundamental se consubstancia num vetor de muitas ilegalidades socioespaciais do ponto de vista da legislação urbanística e do código de edificações de obras, contrariando, assim, os modelos de apropriação e organização do espaço urbano estabelecidos nas regulamentações jurídicas vigentes. Essas práticas de inserção ilegal na cidade, sob o ponto de vista do Estado, têm, no entanto, e historicamente, se constituído nas alternativas possíveis de "resolução" do problema do como e onde morar entre segmentos sociais de baixa renda (BAGGIO, 1995, p.11- 
12), cujas expressões socioespaciais integram amplas parcelas de nossas periferias urbanas, principalmente.

Com os influxos da financeirização no mercado imobiliário, define-se uma lógica de produção massiva da casa-mercadoria, que tem impulsionado, por ações do Estado, as remoções de populações empobrecidas de lugares de submoradia, com a contrapartida de produção de conjuntos habitacionais em espaços periféricos, não raro com carências e insuficiências de infra-estruturas e serviços, acentuando dificuldades ainda maiores de reprodução social e qualidade de vida. Está se abrindo a passos rápidos uma frente político-urbana bastante lucrativa ao capital financeiro, multiplicando inversões no urbano. As transformações espaciais pelas quais a cidade tem passado avançam a passos rápidos, porém produzindo conflitos e resistências. Embora se possam identificar conquistas auspiciosas por movimentos e outras lutas urbanas, envolvendo confrontos com poderes hegemônicos, estes ativismos ainda se mostram, ao menos por enquanto, e de modo geral, um tanto que fragmentadas, porquanto venham ampliando e fortalecendo suas articulações, pesando para isso o uso de novas tecnologias comunicacionais que, operam, de fato, redimensionamentos à política.

O contexto de crise que emerge em fins dos anos 1960 e início dos 70, assinala o esgotamento do padrão fordista de acumulação e a transição rumo a um novo padrão, que David Harvey designa de "acumulação flexível" (1992), deflagrando a própria crise das economias de aglomeração fordistas. Tal crise impulsionou movimentos de desconcentração espacial do capital industrial, representando um primeiro momento de formação de novas aglomerações e centralidades urbanas. Este movimento de criação de novas aglomerações plurimunicipais recrudesce sob o desenvolvimento da terceirização, que avança sob a crise atual, impondo-Ihes uma maior densidade em seus sistemas de relações, conferindo grande dinamismo e projeção ao setor de serviços, sob a preponderância do setor financeiro e seus vultosos aportes na expansão e reestruturação do espaço. Edward Soja nos esclarece o seu significado mais abrangente, ao assinalar que: 
“A reestruturação, em seu sentido mais amplo, transmite a noção de uma 'freada', senão de uma ruptura nas tendências seculares, e de uma mudança em direção a uma ordem e uma configuração significativamente diferentes da vida social, econômica e política. Evoca, pois, uma combinação sequencial de desmoronamento e reconstrução, de desconstrução e tentativa de reconstituição, proveniente de algumas deficiências ou perturbações nos sistemas de pensamento e ação aceitos. A antiga ordem está suficientemente esgarçada para impedir os remendos adaptativos convencionais e exigir, em vez deles, uma expressiva mudança estrutural”.

[...] "A reestruturação não é um processo mecânico ou automático, nem tampouco seus resultados e possibilidades potenciais são predeterminados. Em sua hierarquia de manifestações, a reestruturação deve ser considerada originária de e reativa a graves choques nas situações e práticas sociais preexistentes, e desencadeadora de uma intensificação de lutas competitivas pelo controle das forças que configuram a vida material. Assim, ela implica fluxo e transição, posturas ofensivas e defensivas, e uma mescla complexa e irresoluta de continuidade e mudança. Como tal, a reestruturação se enquadra entre a reforma parcial e a transformação revolucionária, entre a situação de perfeita normalidade e algo completamente diferente" (SOJA, 1993, p.193-194).

Com efeito, essa "freada" implica em mudanças, concomitantemente, no tempo e no espaço, redimensionando as práticas sociais, que assim recobrem tanto a cidade como o campo, manifestando-se, de forma geral, por uma maior segmentação territorial da cadeia produtiva e criação de novas funcionalidades, imprimindo uma maior fragmentação e redefinindo disparidades territoriais, potencializando, entre outros aspectos, processos de segregação socioespacial, aumentando desigualdades. A estreita articulação entre a reestruturação e a espacialidade traduz uma tentativa de o capitalismo ajustar, de forma reativa, suas matrizes temporais e espaciais (SOJA, 1993), movimento que recobre tantos países de industrialização originária (nesses com maior contundência), como espaços da periferia do sistemamundo, como vem ocorrendo na América Latina, e, de modo espetacular, no Brasil. As transformações socioespaciais daí decorrentes, que mobilizam associativamente 
a reestruturação produtiva e a adoção de políticas neoliberais, sinalizam para o fato de que as cidades, mais do que antes, estão sendo estruturadas e geridas, principalmente, em observância às demandas do capital, em grande descompasso com as demandas sociais. De forma relacionada, a queda acentuada do emprego na indústria, a ampliação da terceirização, o rebaixamento de salários e direitos, entre outros condicionantes, só fazem aumentar as disparidades socioespaciais, as compressões e os desatinos na vida cotidiana urbana, notadamente em grandes conglomerados urbano-metropolitanos.

Indubitavelmente o capital financeiro tem respondido por alterações socioespaciais expressivas, principalmente nos espaços metropolitanos, mas também em cidades médias, em franco movimento ascensional. A criação dessas novas centralidades e funções imprime novas dinâmicas de valorização econômica do espaço, bastante associadas ao crescimento exponencial do uso do automóvel em nossa sociedade e, relacionadamente, à ampliação da rede viária. Nesse sentido, os vetores de expansão urbana mais atual consubstanciam-se ao longo de grandes artérias de circulação automobilística, favorecendo, entre outras coisas, a expansão dos condomínios fechados em setores mais periféricos da cidade. $O$ automóvel, uma vez mais, comparece como um dado fundamental ao espraiamento do tecido urbano. Á medida que tais empreendimentos imobiliários se multiplicam intensiva e extensivamente, conferindo uma tendência na urbanização atual (recobrindo tanto cidades grandes, médias e mesmo pequenas), a motorização da sociedade recrudesce, impondo-se de forma incisiva, quase que coercitivamente, influindo efeitos deletérios na vida de parcelas crescentes da população. Assim, elas se tornam submetidas a uma conformação urbana cada vez mais fragmentada, desigual e buliçosa, substancialmente condicionada ao desenvolvimento da terceirização e, em especial e de forma associada, à circulação automobilística. Situações diversas na América Latina podem ser identificadas e, em especial, no Brasil, caso bastante emblemático desse processo.

É flagrante, pois, que a generalização do uso do automóvel em nossa sociedade, notadamente em ambientes urbanos, passou a representar um componente de 
compressão e perturbação ao meio ambiente e à vida cotidiana, também se projetando como um problema de saúde pública. Respondendo por congestionamentos regulares, poluição atmosférica, sonora e visual, acidentes em grande escala, acidificação, impactos em edifícios e monumentos históricos, sedentarismo/obesidade, perturbação da atenção, problemas respiratórios e cardíacos, irritabilidade, entre outros problemas, o uso generalizado do automóvel representa, assim, a formação ampliada de um ambiente degradante e degenerativo em nossas cidades. No Brasil, país marcadamente rodoviarista, os grandes centros urbanos se transformaram em verdadeiros infernos motorizados.

Temos que essa centralidade do uso do automóvel implique numa forma de vida urbana na qual a relação entre as pessoas e destas para com a cidade torna-se cada vez mais mediada pelo acelerador, sinalizando uma espécie de agravo às condições de alienação socioespacial, quando o caminhar e a fruição paisagística, que criam ambiências e relações mais diretas entre as pessoas e destas para com os lugares, declinam sob o reino da motorização automobilística da sociedade, o que comparece como uma expressão basilar da prevalência da lógica da mercadoria no processo social.

Para muitos o automóvel se metamorfoseou numa extensão ou anexo do próprio corpo, havendo certa percepção de que sem ele a vida moderna praticamente se inviabilizaria. Há evidências de que já tenha se tornado algo mais ambicionado e valorizado do que a própria moradia ou lugar de residência, não raro sendo alçado à condição de projeto de vida. É insuficiente, pois, justificar o maior uso do automóvel por deficiências reais do sistema de transporte público, o que também não deixa de ser verdade. No entanto, parece haver fortes indícios que a simples melhoria desse sistema não seria capaz de inverter essa condição.

A centralidade adquirida pelo automóvel na sociedade moderna implica, pois, na transformação da rua (um espaço público) em lugar de passagem e fluxos, tornandose um espaço duplamente cindido, isto é, como lugar de passagem de pedestres, que nela se acotovelam sob o tempo ritmado do trabalho, e como via privilegiada de 
circulação de automóveis, o que sugere, ao lado de outras variáveis, uma espécie de apropriação privativo-mercadológica da rua, para a qual o automóvel exerce efeitos condicionantes e indutores fundamentais. Nesse sentido,

"A invasão dos automóveis e a pressão dessa indústria, isto é, do lobby do automóvel, fazem dele um objeto-piloto, do estacionamento uma obsessão, da circulação um objetivo prioritário, destruidores de toda vida social e urbana. Aproxima-se o dia em que será preciso limitar os direitos e poderes do automóvel, não sem dificuldades e destruições" (LEFEBVRE, 1999, p.29).

Tal transformação da rua representa, pois, a proeminência conflitante da troca e do valor de troca em relação ao uso e ao valor de uso, que comporta um sentido de certa mortificação da rua, o que não se dá, todavia, sem resistências e reações. $E$ isso em razão dela representar historicamente um lugar de encontro e sociabilidade importante à vida urbana, suscitando "outros encontros possíveis" em lugares determinados, que se instalam junto às suas calçadas, tais como botequins, cafés, lanchonetes, restaurantes, espaços culturais, mercados municipais, praças e casas noturnas. Ainda que tais lugares estejam submetidos aos influxos transformadores da urbanização/metropolização atual, eles, ainda assim, e dentro de certos limites, favorecem a formação de atmosferas relacionais que animam a vida urbana, promovendo aproximações entre as diferenças e os desiguais, favorecendo convivências. São aspectos que representam contrapontos importantes a tendências segregacionistas na cidade. O que não faz da restituição da rua a "solução" a esse grave problema, conquanto enseje outras possibilidades à vida urbana, em meio aos influxos de um cotidiano fragmentado e submetido a uma ordem acentuadamente burocratizada, prenhe de aspectos coercitivos e repressivos.

Diante disso, e em sua defesa, pode-se enunciar que:

"Onde quer que a rua desapareça, a criminalidade aumenta, se organiza. Na rua, e por esse espaço, um grupo (a própria cidade) se manifesta, aparece, apropria-se dos lugares, realiza um tempo-espaço apropriado. Uma tal apropriação mostra que o uso 
e o valor de uso podem dominar a troca e o valor de troca" (LEFEBVRE, 1999, p.30 grifos do autor).

Em face desse cenário a rua e a cidade e, com efeito, a vida cotidiana clamam por redimensionamentos socioespaciais e político-societários, em que pesem a atuação de vetores proeminentes da apropriação capitalista do espaço, turbinada, como se viu, pela financeirização da economia. As demandas do uso e do valor de uso põemse, assim, em conflito direto com os processos em curso de valorização econômica do espaço, tanto em áreas centrais, principalmente de grandes centros, como em espaços periféricos, recobrindo a formação de eixos aglomerativos de expansão tendencial da cidade, não sendo demais frisar o papel indutor representado pelo automóvel nesse processo.

Nas áreas centrais, essa valorização tem sido deflagrada, de modo geral, por projetos de revitalização urbana conduzidos pelo Estado, não raro envolvendo parcerias com agentes financeiros, que, com freqüência, precipitam a gentrificação urbana, processo que, em grande medida, inviabiliza a permanência de segmentos sociais mais empobrecidos nessas áreas, tais como moradores de cortiços, etc., que não conseguem arcar com os custos locacionais advindos dessas operações urbanas. Ocorre, assim, uma substituição progressiva desses segmentos sociais por outros de maior poder aquisitivo, como se pode notar com a implantação de novos negócios nesses espaços revitalizados, como lojas de grife, casas noturnas, novos hotéis, restaurantes e bares "mais sofisticados", etc. O que nos parece importante reter aqui é que, além de produzir mudanças sociais e morfológicas de monta na cidade, a gentrificação responde pela imposição de uma racionalidade de caráter espoliativo e segregacionista, que potencializa desigualdades e tensões no espaço urbano.

A elevação da renda da terra cobrada pelos proprietários, advinda de tais projetos de revitalização, sob o manto da cultura e do resguardo de patrimônios, opera na base desse processo de invasão e sucessão na cidade. Salientamos, a propósito, que é através das inversões do capital financeiro no espaço que a terra-mercadoria se metamorfoseia em capital imobiliário, um ativo financeiro que comparece então sob a 
forma de uma nova base de edificações (reabilitadas, modificadas ou substituídas por outras) e funções urbanas. Evidencia-se, portanto, que esse processo de valorização atua como um vetor robusto de desigualdade socioespacial, vetor que se realiza por uma estreita associação entre o Estado e o capital, com o primeiro atuando como o representante maior dos interesses corporativos, em detrimento dos da maioria da sociedade. A tipificação desta associação comporta, portanto, o sentido de um projeto de sociedade desigual, que se expressa como desigualdade jurídica, da riqueza e em face da cidadania, logo como desigualdade socioespacial.

Reafirma-se, nessa direção, que o espaço tenha se convertido, efetivamente, numa base segura e preferencial à valorização do capital, sobretudo em ciclos crise, propiciando-Ihe condições reprodutivas que, de modo geral, são criadas principalmente pelo Estado. Podem-se oferecer como exemplo as estratégias de alocação geográfica de capitais desvalorizados, fazendo multiplicar inversões que, de modo geral, potencializam a sua concentração, ou ainda a sua supermonopolização à escala global, incrementando processos de produção corporativa do território.

Essa dinâmica expansivo-concentracionista se constitui num aspecto marcante da espacialidade capitalista contemporânea e, desse modo, do próprio desenvolvimento desigual atual, recrudescendo substantivamente as disparidades espaciais. "E quando há desigualdade geográfica no desenvolvimento capitalista, há transferências geográficas de valor" (SOJA, 1993, p.139); transferências que, segundo Soja, se definem como mecanismos ou processos pelos quais "parte do valor produzido em dada localidade, área ou região é realizado em outra, somando-se à base de acumulação localizada da região receptora" (p.140). Tais mecanismos deflagram novas relações de exploração nos lugares de recepção, estabelecendo uma espacialidade mutável que se assemelha à da estrutura centro-periferia, porém dotada de maiores estratificações, entabulando-se como verdadeiros mosaicos empíricos multifractalizados, que, ao mesmo tempo em que expressam o desenvolvimento geograficamente desigual do capitalismo globalizado contemporâneo, também se revelam solidamente articulados a ele, integrados, assim, à sua lógica de realização. 
David Harvey (2004) põe em evidência o fato de que, no ciclo atual do capitalismo, tal mecanismo de transferência vem acompanhado de práticas espoliativas crescentes, produzindo impasses, conflitos e restrições à própria acumulação. Pode-se compreender, então, que esta dimensão espoliativa do novo padrão de acumulação potencializa assimetrias espaciais e conflitos no âmbito da reprodução social, envolvendo, entre outros aspectos, despossessões e privatizações de bens públicos, projetando-se, assim, como espoliação socioterritorial. Comportando o sentido de uma exploração recrudescida do trabalho, a acumulação por espoliação, em curso, materializa-se como um aspecto marcante da urbanização e do urbano na contemporaneidade.

$\mathrm{Na}$ esteira desse novo padrão de acumulação os níveis de concentração da riqueza mundial aumentam, exacerbando desigualdades, especialmente a partir dos anos 1970-1980, engendrando significativas assimetrias socioespaciais entre países, o que sugere, de acordo com Thomas Piketty (2014, p.233), que "as diferenças institucionais e políticas tenham exercido um papel central" na produção desses contrastes, cenário em que se podem encontrar empresas-corporações ostentando faturamentos superiores a PIBs de países inteiros. No que concerne, mais especificamente, à desigualdade das rendas, o autor assinala que a desigualdade do capital tem se mantido regularmente acima da do trabalho; regularidade que "em si nada tem de evidente", revelando, com exatidão, "a natureza dos processos econômicos e sociais que governam a dinâmica da acumulação e da distribuição dos patrimônios" (p.240). Daí que "a distribuição da propriedade do capital e das rendas que dele provém" apresentar-se "sistematicamente mais concentradas do que a distribuição das rendas do trabalho", pesando, para isso, o fato de que a "forte acumulação do capital" verificada nos tempos atuais se encontrar estreitamente atrelada ao recebimento de heranças (capital herdado) e seus efeitos cumulativos, favorecendo mecanismos de poupança (p.239). O que não quer dizer, adverte o economista, que se deva negligenciar a desigualdade das rendas do trabalho em relação às do capital, haja vista que as primeiras expressam parcelas expressivas da renda nacional, entre dois terços e três quartos, aproximadamente; além de sua distribuição se mostrar sempre 
bastante desigual entre os diversos países. Isso revela que as políticas públicas e as diferenças nacionais podem ter implicações importantes na conformação das desigualdades e das condições de vida de grandes parcelas da população (p.250).

Nesse mesmo contexto, percebe-se ainda que a avassaladora financeirização da economia, proporcionada em grande medida pela desregulametação do fluxo de capitais e o espetacular desenvolvimento das tecnologias de comunicação, tem conduzido a um duplo movimento de variáveis correlacionadas. De um lado, tem-se "um processo recorrente de desvalorização do trabalho, com uma progressiva precarização das condições de emprego e de remuneração", e, do outro, do "recorrente desemprego", conduzindo à deterioração do mercado, das relações de trabalho e da política social, desembocando "no aumento generalizado da desigualdade econômica e social nas nações desenvolvidas e em desenvolvimento" (DEDECCA, 2010, p.2), embora a pobreza, de modo geral, tenha diminuído no mundo, conquanto a distância entre os mais ricos e os mais pobres tenha aumentado, o que aponta para um maior enriquecimento de uma minoria, por conseguinte produzindo uma concentração ainda maior da riqueza.

Sobretudo na periferia do sistema-mundo e, em especial, na América Latina, as disparidades socioespaciais agudamente contrastantes comportam inteiramente o sentido de uma oposição degradante, que tanto recobre como incita a multiplicação de fronteiras e divisórios monitorados entre os espaços desiguais.

No âmbito do mercado pode-se identificá-la na dualização entre, de um lado, atividades mais avançadas e tecnificadas, mais bem remuneradas e mais robustas, e, de outro lado, um amplo segmento de características inversas. Não se trataria exatamente de uma dualidade integrada, mas mais propriamente de uma unidade contraditória e desigual do próprio processo capitalista, que encerra uma correspondente espacialidade desigual, recaindo-lhe os condicionantes e determinações da crise atual. Tem-se, assim, a formação de um mercado de trabalho bastante segmentado, revelador de uma expressiva polarização social. Diante dessa situação, as funções reguladoras e assistenciais do Estado sofrem uma sensível 
retração, ao mesmo tempo em que se flexibilizam as relações de trabalho, fragilizando-as. Ao lado do aumento do desemprego, isso resulta na ampliação dos níveis de informalidade da economia, influindo uma maior precarização ao mercado de trabalho e, portanto, à própria reprodução social.

Tal condição socioespacial implica, seguramente, em restrições ao direito à cidade a um número crescente de pessoas, sugerindo que a urbanização tenha de fato se tornado crítica, no sentido de expressar-se como impossibilidade do urbano para todos. Tem-se assim um urbano e uma cidade que se constituem pela negatividade do trabalho, que comporta inteiramente o sentido do trabalho alienado, não se apresentando, de modo geral, como atividade criadora, como fonte viva do valor, mas mais propriamente como um meio à manutenção da existência física do trabalhador, que não aspira, na maioria das vezes, outra coisa que não o consumo conspícuo.

Nas circunstâncias contemporâneas de uma irrefreável mercantilização do espaço, com o Estado coordenando ações na cidade de modo a torná-la competitiva e atrativa a novos investimentos, sob o sentido da maior capitalização possível, essa orientação não tem apresentado, de modo geral, maiores contrapartidas em termos de desenvolvimento social e ambiental, conquanto ela se realize sob a roupagem ideológica da sustentabilidade, o novo vetor midiático a nortear os grandes empreendimentos empresariais no espaço, a exemplo de projetos voltados à criação de condomínios fechados, que se afirmam como uma tendência na urbanização atual.

A propagação geográfica dessas formas urbanas, inclusive em cidades de pequeno porte, consolida um urbanismo de enclaves, evidenciando uma modalidade expansiva de apropriação privada da cidade e de multiplicação de descontinuidades no tecido urbano. Elas se multiplicam com a demarcação mais rigorosa da separação, acentuando sensivelmente, ao lado de outras variáveis, a transformação da cidade numa espécie de anticidade, que assim se conforma sob o caráter da segregação, da desigualdade, da violência, do medo, da insegurança e da desconfiança generalizados. 
Esse cenário de recrudescimento e atualização das desigualdades socioespaciais, fragilizam, substancialmente, as instituições democráticas, dificultando a participação e o consenso, conquanto o direito à participação esteja formalmente garantido. $E$ tanto os problemas da participação social como os da própria representatividade solicitam mudanças na forma da própria política, no sentido de a sociedade gravitar mais em torno de si do que do Estado (e da estadolatria), não o encarando como mediação única ou exclusiva nas práticas sociais. Por práticas sociais, esclareça-se, se compreende tantas ações conduzidas por movimentos e outras formas de organização político-social, como também práticas teóricas, que interagem sob o sentido de uma dialética enriquecedora.

A perspectiva política aludida não significa, no entanto, a desqualificação ou negação do Estado, ou ainda a recusa de alguma forma de autoridade válida e legítima, o que também recobre lideranças e/ou porta-vozes de movimentos e outras formas de ação. O que não se confunde com uma condição de cooptação subordinada ao Estado, mas, mais propriamente, de uma via norteada por uma inserção efetivamente participativa e diversificada das pessoas na vida política, no sentido de uma atuação mais potencializada e pluralista, coibindo ou mesmo neutralizando domínios coercitivos de pensamento e poder. Ela recobriria tanto o direito de se exercer práticas sob o sentido da democracia direta, como também o aperfeiçoamento contínuo da democracia representativa, desestimulando tanto extremismos de direita, como expressões de caráter ultraliberal. Estas forças, como bem se sabe, colocam em risco a própria democracia, do mesmo modo que em nada contribuem à destruição/superação do capitalismo e, muito menos, à criação de uma "outra" e melhor forma de organização societária.

Não obstante, novos arranjos político-institucionais se fazem necessários, tais como a reforma política, que, para além de combater problemas concernentes à corrupção, componente que alimenta as desigualdades, se orientaria também ao equacionamento da crise de representatividade e do aperfeiçoamento/ampliação das formas de participação social na vida política, coibindo ou desestimulando práticas de aparelhamento e loteamento do Estado. Além da reforma política, urge também a 
realização de uma reforma tributária, promovendo-se uma revisão mais estrutural da questão, tendo-se em vista um sistema mais federalista, obstando a guerra entre os estados e os lugares. Esta reforma deveria tributar mais a renda do que o consumo, simplificando, ainda, os tributos que incidem sobre ele, entre outros aspectos. Acrescente-se, ainda, a necessidade premente de se avançar a reforma urbana no país, que enfrenta, como se sabe, grandes dificuldades. Ela esbarra em poderosos interesses econômicos em torno do espaço, recobrindo o próprio Estado, recaindoIhe interferências substanciais de classes sociais dominantes. Acerca disso reitera-se que no estágio atual da urbanização, o planejamento urbano encontra-se bastante submetido à lógica das empresas e dos negócios, com o Estado desempenhando o papel de provedor de condições ao lucro dos investidores, impulsionando-se a abertura de frentes de valorização do capital no espaço, portanto de produção e apropriação de mais-valia. Urge, ademais, realizar a reforma da previdência, cujo sistema atual se constituiu numa fonte permanente de forte endividamento do Estado.

Ao lado de outras reformas de base não menos importantes, essas reformas são imprescindíveis ao impulso do desenvolvimento econômico, social e territorial, pondose em perspectiva a priorização quanto a políticas que sejam efetivamente capazes de reduzir as desigualdades e fortalecer os direitos sociais.

Por outro lado, nos permitimos indagar até que ponto o capitalismo, em seu movimento contraditório e, sobretudo, sob condições periféricas, permite a construção de uma democracia mais avançada, de modo a favorecer uma efetiva redução das desigualdades e da justiça social. Seria mesmo verdade que o capitalismo corrobora a democracia, como muitos acreditam? A vida urbana cotidiana não estaria se transformando (na periferia, precipuamente, mas também em partes do centro) em situações nucleares de economias de desapropriação, ao mesmo passo que de economias de exploração, com fortes traços espoliativos? Veja-se, por exemplo, as mudanças que estão se processando no mundo do trabalho, envolvendo a precarização dos vínculos trabalhistas, a orientação do trabalho sob meta de resultados (e as pressões permanentes para alcançá-los), instabilidade no emprego, temores diante da possibilidade constante do desemprego, rotina massacrante; enfim, 
um conjunto de componentes geradores de angústia, sofrimento, estresse, síndrome de Burnout (conhecida como síndrome de esgotamento profissional) e depressão. São, indubitavelmente, expressões preocupantes do trabalho, mais especificamente do trabalho alienado, desumanizador, que avança celeremente e se universaliza com a globalização e sua máquina de acumulação espoliativa. Coercitivamente modula-se o trabalho às necessidades do capital, fazendo dessa condição um dado inexorável e "natural" de sua realização. Sob tal condição, pode-se falar da formação ampliada de uma espécie de reino do não-trabalho, do trabalho como negatividade, cujas formas compressivas e inseguras relacionadas à sua organização atual potencializam uma dupla condição de aviltamento, tanto do trabalho em si (das suas condições) como do trabalhador.

Eis um componente que nos parece da maior importância para compreendermos mais a fundo o sentido da crise atual, que também reverbera ou se manifesta como crise da própria cidade, invasivamente submetida à racionalidade do trabalho e do mercado, que operam sob a lógica de uma reprodução ampliada do capital, orientada, portanto, a extração de "super-lucros", ou ainda à obtenção de margens de ganho superiores à taxa média de lucro. Sob esta condição impõe-se como um dispositivo fundamental e estratégico às atividades regulares dos agentes capitalistas a diferenciação socioespacial, produtora de contrastes ameaçadores e potencialmente explosivos.

\section{PRÁTICAS SOCIOESPACIAIS EMERGENTES: CONTRAPONTOS POLÍTICOS NA VIDA COTIDIANA URBANA}

Sob as injunções de uma urbanização crítica, produtora de desigualdades e compressões no urbano, resistências e lutas político-espaciais emergem em face de um conjunto de adversidades vividas, encetando ao plano da vida cotidiana uma diversidade de ações de caráter propositivo e formas de mobilização dotadas, em boa parte, de certo traço auto-organizacional, comportando sentidos de transformação e emancipação. De modo geral elas guardam certo distanciamento do Estado, mas não necessariamente negando-o. Estes ativismos urbanos têm conseguido certas

Disponível em: https://www.nucleodoconhecimento.com.br/ciencias-sociais/realidade-compressivae-conflitual 
conquistas, auspiciosas, em torno de questões variadas, tais como moradia, mobilidade urbana, patrimônio arquitetônico-urbanístico e cultural, lazer, meioambiente, cultura, etc. Embora não se possa dizer, ao menos por enquanto, que protagonizem transformações de fundo da cidade e da vida urbana, elas representam um vetor de estímulo à problematização dessas questões, que permeiam e condicionam a vida urbana, despertando o interesse de um número cada vez maior de pessoas e setores da sociedade, com demandas reprimidas ou não satisfeitas, não raro negadas pelo Estado. Desse modo, essas forças contribuem à ampliação de perspectivas e possibilidades operacionais ao tratamento de problemas urbanos, representando, de certo modo, contrapontos à lógica impositiva e unilateral da racionalidade econômica. Com efeito, suas ações e estratégias favorecem substancialmente a certa reativação do uso social de espaços públicos, por conseguinte beneficiando a vida urbana.

Em seu conjunto essas práticas pontuam em diversos lugares e regiões da cidade, sobretudo nas periferias urbanas, onde, de modo geral, as demandas se mostram mais incisivas. Assim, suas ações e experiências politizam temas e demandas importantes do urbano, imprimindo-Ihes visibilidade pública. Elas se valem, entre outros meios, de aportes de novas tecnologias comunicacionais, como a internet e as redes sociais.

Em muitos ambientes periféricos infra-urbanizados que proliferam na esteira da urbanização extensiva, marcados por edificações e um quadro urbanístico degradados, com ampla predominância de trabalhadores dispersados e distanciados de centros e lugares mais bem dotados de serviços, infra-estruturas e emprego, as lutas em torno da moradia e benfeitorias urbanas têm sido uma constante, nos quais o urbano e o rural se fundem e se confundem, sob os termos de uma urbanização restritiva e segregadora, que incita tanto práticas social e ambientalmente deletérias, como ações de caráter reativo à melhoria das condições de vida.

Dotadas de significativa vitalidade e versatilidade, esses ativismos urbanos forjam nas margens e interstícios de espaços urbanos atmosferas político-sociais ruidosas, 
mobilizando desejos e potenciais inventivos, propugnando formas mais estimulantes de relacionalidade e de uso do tempo e do espaço, que indagam e ampliam os próprios significados da cidade e do urbano, ampliando, ademais, as próprias possibilidades da democracia, enriquecendo-a para além de orientações demasiado estado-cêntricas. Eles comportam, portanto, um sentido mais auto-organizacional à vida política, o que não nega, reitera-se, o Estado, mas potencializa as forças de transformação social. Estas práticas conferem, assim, maior empoderamento aos sujeitos sociais quanto à elaboração e ao desenvolvimento de projetos e ações em torno de demandas que mais diretamente afetam as suas vidas, representando respostas possíveis ou mesmo contrapontos político-qualitativos a certa reinvenção processual da própria vida cotidiana. Pelas beiradas e interstícios do espaço-tempo presente, talvez estejam delineando uma possível nova filosofia de vida, inscrevendose reativamente no fulcro de uma espacialidade contraditória e desigual, amalgamada a um cotidiano capitalista invasivamente consumista, tensionado e coercitivo, mas que, no entanto, não representa uma espécie de fim da história ou via de mão única. Sob o recrudescimento das contradições contemporâneas, pode-se mesmo sublinhar que tais forças de caráter auto-organizacional não só muito provavelmente crescerão no Brasil e no mundo, como talvez representem esperanças factíveis de grande relevância no processo político-social contemporâneo, portanto com implicações não menos importantes na esfera espacial, sob o sentido de uma unidade dialética de dupla determinação.

\section{CONSIDERAÇÕES FINAIS}

A diversidade que marca os ativismos urbanos em curso nos permite perceber e compreender que a vida também pulsa reativamente sob as contradições e embates do cotidiano, sugerindo-nos, de certo modo, gestações políticas sob o sentido de uma utopia concreta, que emerge ao plano do possível, portanto engendrada no tempo presente. São componentes auspiciosos que a análise valoriza na pesquisa sob o procedimento metodológico da transdução, isto é, da reflexão sobre o objeto possível (LEFEBVRE, 1999, p.18). A transdução se abre, com efeito, à via do que pode ser realizado, sem, no entanto, se restringir ao que está dado e realizado, submetido

Disponível em: https://www.nucleodoconhecimento.com.br/ciencias-sociais/realidade-compressivae-conflitual 
plenamente às determinações das forças econômicas, sociais e políticas presentes, ou seja, pondo-se também como aferição crítica prospectiva, que guarda certa distância do "real" tal como é, mas sem, no entanto, perdê-lo de vista, para pensá-lo quanto ao que ele poderá ser. Isso não significa, é forçoso esclarecer, projetar para o futuro a resolução dos problemas que nos afligem, mas tomá-los, a partir de suas contradições e possibilidades ou sinalizações que se insinuam no tempo presente, em perspectiva transformacional.

É sob essa perspectiva que se pode postular que não pode haver pensamento e práticas sociais responsáveis que não persigam uma utopia, reiteradamente no sentido de uma utopia concreta, que incorpora a idéia de possibilidade como um horizonte factível à consecução do desejo e da necessidade, enredando-se como possibilidade real num dado âmbito socioespacial. Ela se apoia em expressões e virtualidades sociais capazes de sugerir ou sinalizar outros e mais desejáveis caminhos em meio ao nivelamento redutor que incide na vida social, não se confundindo, assim, com mera boa fé, visões idealistas ou posturas meramente contemplativas da realidade. Ela não se põe, por conseguinte, como algo fantasioso ou quimérico, não se mostrando aos sentidos como simples derivação da imaginação humana, mas como uma perspectiva lastreada na realidade e referenciada por ela, comportando potencialidades à própria transformação da sociedade e, assim, do próprio espaço.

Falamos, portanto, de um pensamento e de umas práxis que em essência são inseparavelmente articulados, que não se resignam ao constatado, ratificando-o, mas que se colocam em efetiva consonância com uma transformação socioespacial mais de fundo. O que solicita maior protagonismo e envolvimento dos próprios interessados, fomentando cotidianamente situações mais avançadas de exercício da democracia, pela qual as pessoas possam ter maior controle e participação em políticas e ações que repercutem em seu processo de vida.

Todavia, a consecução de uma desejável e mais virtuosa transformação dos territórios e dos modos de vida não logrará êxito sob a restrição da hegemonia corrosiva das 
forças do mercado e do pensamento único. Se a economia, colada ao espaço, reiteradamente nos dá evidências de que alçou os negócios ao seu interesse maior, tornando-se praticamente esvaziada de preocupações quanto aos grandes problemas sociais, temos que o equacionamento dessa condição socioespacial crítica, desigual e compressivo-conflitual, em muito dependerá, mas não de forma unívoca ou exclusiva, de prodigalizações de práticas e estratégias politicamente mais estimulantes e influenciadoras de se estar e atuar no mundo prático-sensível. Elas implicam, nesse sentido, um duplo senso de responsabilidade, concomitantemente social e espacial, que compreende e valoriza as diferenças, portanto relações próximas e distantes, percebidas e concebidas, não compactuando com as desigualdades e segregações, muito menos legitimando ou naturalizando-as.

Os problemas representados pela desigualdade e compressões da vida cotidiana não encontram equacionamento e tratamento adequado sob uma lógica orientada proeminentemente ao crescimento econômico, sendo-lhe subjacente a idéia de que o bem-estar material é condição ou pressuposto a formas melhoradas de vida. Nos termos em que essa questão tem sido tratada no Brasil, torna-se ainda mais patente que a consecução de uma condição socioespacial efetivamente mais equilibrada, portanto menos desigual e compressiva, não deve se restringir tão somente a remanejamentos territoriais de atividades, solicitando o concurso de reformas imprescindíveis das estruturas sociais e políticas, adrede mudanças qualitativas nas próprias subjetividades.

Com efeito, ganha relevância o papel representado pelas ciências humanas, conjuntamente ao de movimentos sociais, ativismos urbanos e forças progressistas da sociedade, quanto à elaboração de uma nova ética socioespacial, desembaraçada de reificações e subjetividades mercantilizadas, orientada a uma integração mais ativa e responsável entre as pessoas e para com os lugares de vida e labor. 


\section{REFERÊNCIAS}

BAGGIO, Ulysses da C. A dinâmica das transformações socioespaciais das formas de submoradia no município de São Paulo. São Paulo: Faculdade de Filosofia, Letras e Ciências Humanas da Universidade de São Paulo, 1995. Dissertação de Mestrado em Geografia.

BECKER, Berta K.; EGLER, Claudio. Brasil: uma nova potência regional na economiamundo. 2 $2^{\mathrm{a}}$. edição. Rio de Janeiro: Bertrand Brasil, 1994.

CAPRA, Fritjof. O ponto de mutação. São Paulo: Cultrix, 1995.

CARLOS, Ana F. A. A tragédia urbana. In: Carlos, Ana F. A. et al. (orgs.) A cidade como negócio. São Paulo: Contexto, 2015. p.43-63.

CORRÊA, Roberto L. Região e organização espacial. São Paulo: Ática, 1986.

DEDECCA, Claudio S. Trabalho, financeirização e desigualdade. Texto para discussão. IE/UNICAMP. n.174, abr. 2010.

FERRY, Luc. A inovação destruidora: ensaio sobre a lógica das sociedades modernas. Rio de Janeiro: Objetiva, 2015.

HARVEY, David. O novo imperialismo. São Paulo: Loyola, 2004.

LEFEBVRE, Henri. A revolução urbana. Belo Horizonte: Editora UFMG, 1999.

LEFEBVRE, Henri. Espaço e política. Belo Horizonte: Editora UFMG, 2008.

MANDEL, Ernest. O capitalismo tardio. 2ª . edição. São Paulo: Nova Cultural, 1985. (Coleção "Os Economistas")

MARTINS, José de S. O cativeiro da terra. São Paulo: Hucitec, 1990. 
MORAES, Antônio C. R. Território e história no Brasil. 2a . edição. São Paulo: Annablume, 2005.

SOJA, Edward W. Geografias pós-modernas: reafirmação do espaço na teoria social crítica. Rio de Janeiro: Jorge Zahar Editor, 1993.

PIKETTY, Thomas. A economia da desigualdade. Rio de Janeiro: Intrínseca, 2015.

PIKETTY, Thomas. O capital no século XXI. Rio de Janeiro: Intrínseca, 2014. 